\title{
Partnership among hospitals to reduce healthcare associated infections: a quasi- experimental study in Brazilian ICUs
}

Ladjane Santos Wolmer de Melo ${ }^{1}$, Maria Verônica Monteiro de Abreu', Bernuarda Roberta de Oliveira Santos², Maria das Graças Washington Casimiro Carreteiro ${ }^{3}$, Maria Fernanda Aparecida Moura de Souza ${ }^{4}$,

Maria Carolina Andrade Lins de Albuquerque ${ }^{5}$, Claudia Fernanda de Lacerda Vidal ${ }^{1}$ and Heloisa Ramos Lacerda ${ }^{6^{*}}$ (1)

\begin{abstract}
Background: Healthcare-associated infections (HAls) are relevant in developing countries where frequencies can be at least 3 times higher than in developed countries. The purpose of this research was to describe the intervention implemented in intensive care units (ICUs) to reduce HAls through collaborative project and analyze the variation over 18 months in the incidence density (ID) of the three main HAls: ventilator associated pneumonia (VAP), central line-associated bloodstream infections (CLABSIs) and catheter-related urinary tract infections (CAUTIs) and also the length of stay and mortality in these ICUs.

Methods: A quasi-experimental study in five public adult clinical-surgical ICUs, to reduce HAls, through interventions using the BTS-IHI "Improvement Model", during 18 months. In the project, promoted by the Ministry of Health, Brazilian philanthropic hospitals certified for excellence (HE), those mostly private, certified as excellence and exempt from security contributions, regularly trained and monitored public hospitals in diagnostics, data collection and in developing cycles to improve quality and to prevent HAls (bundles). In the analysis regarding the length of stay, mortality, the IDs of VAP, CLABSIs and CAUTIs over time, a Generalized Estimating Equation (GEE) model was applied for continuous variables, using the constant correlation (exchangeable) between assessments over time. The model estimated the average difference ( $\beta$ coefficient of the model) of the measures analyzed during two periods: a period in the year 2017 (prior to implementing the project) and in the years 2018 and 2019 (during the project).

Result: A mean monthly reduction of 0.427 in VAP ID $(p=0.002)$ with $33.8 \%$ decrease at the end of the period and 0.351 in CAUTI ID ( $p=0.009)$ with $45 \%$ final decrease. The mean monthly reduction of 0.252 for CLABSIs was not significant $(p=0.068)$. Length of stay and mortality rates had no significant variation.

Conclusions: Given the success in reducing VAP and CAUTIs in a few months of interventions, the achievement of the collaborative project is evident. This partnership among public hospitals/HE may be applied to other ICUs including countries with fewer resources.
\end{abstract}

Keywords: Healthcare-associated infections, Breakthrough series, Collaborative, Intensive care units, Prevention bundles

\footnotetext{
*Correspondence: helramoslacerda@gmail.com

${ }^{6}$ Department of Clinical Medicine, Federal University of Pernambuco, Recife, Pernambuco, Brazil

Full list of author information is available at the end of the article
}

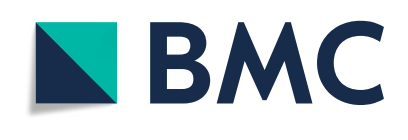

(c) The Author(s) 2021, corrected publication 2022. Open Access This article is licensed under a Creative Commons Attribution 4.0 International Licnese, which permits use, sharing, adaptation, distribution and reproduction in any medium or format, as long as you give appropriate credit to the original author(s) and the source, provide a link to the Creative Commons licence, and indicate if changes were made. The images or other third party material in this article are included in the article's Creative Commons licence, unless indicated otherwise in a credit line to the material. If material is not included in the article's Creative Commons licence and your intended use is not permitted by statutory regulation or exceeds the permitted use, you will need to obtain permission directly from the copyright holder. To view a copy of this licence, visit http://creativecommons.org/licenses/by/4.0/ The Creative Commons Public Domain Dedication waiver (http://creativecommons.org/publicdomain/zero/1.0/) applies to the data made available in this article, unless otherwise stated in a credit line to the data. 


\section{Background}

Healthcare-associated infections (HAIs) are relevant to global public health, especially in developing countries where the frequency may be at least 3 times higher than in developed countries [1]. In Brazil, the incidence density (ID) of HAIs related to devices in the year 2016 indicated ventilator associated pneumonia (VAP) of 13.6/ 1000 days, central line-associated bloodstream infections (CLABSIs) of 4.6/1000 days and catheter-related urinary tract infections (CAUTIs) of 5.1/1000 days [2], while the 2016 European annual report registered IDs for VAP of $3.9 / 1000$ days, CLABSIs of 1.7/1000 days and CAUTIs of $2.1 / 1000$ days [3]. Although these are frequent adverse events, with high morbidity and mortality rates and high costs, HAIs are recognized as being preventable in up to $70 \%$ of cases [4].

Outstanding amongst the strategies for healthcare quality improvement, including the reduction of HAIs, is the Breakthrough Series Collaborative method - BTS, by the Institute for Healthcare Improvement - IHI [5]. Since 1996, this has been implemented in a number of health systems, initially and chiefly in developed economies in North America, Europe and Australia [6], and even in low-to-middle income countries, such as those in Latin America and Africa [7].

In 2018, Susan Wells et al. published the results of a thorough systematic review, studying collaborative methods published between 1995 and 2014 and concluded that, despite methodological limitations and little description regarding aspects of implementation, they were nonetheless effective in improving processes and results. In $83 \%$ of hospital studies, there was an improvement in at least one of the investigated indicators and, when a more conservative criterion was used, this effectiveness was 73\% [8].

In Brazil, where there are interstate and regional socioeconomic differences, quality improvement programs (QIPs) using the BTS collaborative method are still rare, although they were employed in 2015/16 in the southeast of the country for safe childbirth [9] and in intensive care units (ICUs) in Midwest, Southeast and South Brazil in combating HAIs [10], with successful results. However, no publications on QIPs were observed in the current literature in ICUs in the Northeastern region of the country, which has more limited resources [11].

In order to reduce the incidence of HAIs by $30 \%$ in 18 months the Brazilian Ministry of Health promoted the collaborative project "The large-scale improvement of patient safety in Brazil", through the Institutional Development Program of the Integrated Health System (PROADISUS), with BTS large-scale improvement methodology. In this program, Brazilian philanthropic hospitals of excellence (HE) applied their technical capacity and knowledge to promote healthcare improvement in public hospitals across the country (Unified Health System, treated in Brazil by its Portuguese acronym SUS) [1].

The project took place in 119 adult Brazilian intensive care units (ICUs), including about 1200 beds in total. Each of the five Brazilian HE guides 24 institutions in 25 out of 26 existing states and the Federal District throughout the country [12]. Five of which were in the Metropolitan Region of Recife, in the northeast of the country, with a population of around 4 million.

The purpose of this research was to describe how the PROADI-SUS project was implemented in these five ICUs, and to assess whether the $30 \%$ reduction over 18 months goal was achieved, in the incidence density (ID) of the three main HAIs: VAP, CLABSIs and CAUTIs [13], as well as the length of stay and mortality in these ICUs. It should be noted that the majority of existing collaborative projects focus on indicators for only one or two HAIs [8].

\section{Methods \\ Study location}

This study was conducted in 48 adult ICU beds in five public tertiary hospitals in Recife, in the Northeastern region of Brazil, from January/2018 to June/2019. These were clinical-surgical ICUs with an admission rate of around 1800 patients per year.

\section{Study setting and design}

In this quasi-experimental time-series study, interventions were carried and data was collected on a monthly basis for 18 months, including all patients admitted to the ICUs. The methodology was the BTS [5] using the "Improvement model".

Hospital teams were trained by Brazilian philanthropic hospitals certified for excellence (HE) in diagnostics, data collection and in developing cycles to improve quality and to prevent HAIs (VAP, CLABSIs and CAUTIs). In Brazil, according to Decree 8242 of 04/23/2014, HE are those certified for excellence and exempt from social security contributions, as long as part of their services be offered to SUS (Unified Health System, treated in Brazil by its Portuguese acronym SUS). These institutions are mostly private, offering assistance, teaching, and research activities, to qualify the public health system in exchange for the non-payment of taxes that should be collected [14]. These face-to-face and online training sessions took place during periodic sessions for sharing questions, experiences and results. The hospitals received educational visits every 4 months together with online consultations with facilitators on the improvement model, patient safety, intensive care and infectious diseases.

The methodology at the original project and at this study included following instructional diagrams demonstrating the preventive measures for HAIs, implemented 
through PDSA (Plan-Do-Study-Act) rapid cycle testing [5]. PDSAs are improvement tests when changes were first performed with a small group of patients and healthcare professionals, thereby enabling small-scale testing to result in learning and adaptations. Once the process was considered suitable for the local reality and the tests had achieved success, it was progressively implemented throughout the rest of the unit. The implemented improvements were monitored by indicators and the institutions received technical visits from the HE.

After each learning session with specialists in quality improvement and HAIs, with the presence of four representatives from each of the hospitals (local management team), periods of action were initiated, during which the teams returned to their organizations and tested the changes in their contexts.

Result indicators were monitored monthly: incidence densities (ID) of the HAIs, length of stay and mortality in ICUs and process indicators: the rate at which devices were used and adherence to the preventive measures (bundles).

The local teams were instructed to carry out systematic educational observations on the diagnoses and adherence to the bundles, with at least 20 monthly observations per indicator, in order to plan new PDSAs. The established bundles were: 1- VAP: oral hygiene, raised headboard $\left(30-45^{\circ}\right)$, reduced sedation, verifying the possibility of extubation, maintaining the cuff pressure of the tracheal cannula $(25-30 \mathrm{~cm}$ of $\mathrm{H}_{2} \mathrm{O}$ or $20-22 \mathrm{mmHg}$ ) and adequate maintenance of the mechanical ventilation system. 2- CLABSIs: on insertion of the central venous catheter $(\mathrm{CVC})$ - check indications, precautions for maximum barrier, skin antisepsis with chlorhexidine, optimal selection of insertion site, adequate dressing after insertion; maintenance of CVC - indication of permanence, aseptic technique in handling, maintenance of the infusion system, correct dressing technique. 3- CAUTIs: when inserting the urinary catheter (UC) - check indication, aseptic technique; maintenance of the UC - permanence of the closed system, correct technique during drainage manipulation, hygiene of the urethral meatus, check the need to maintain the UC.

The local teams monitored and shared the active PDSAs with the ICU team, on a weekly basis - through rounds -, and the indicators, on a monthly basis. The monthly data on the frequency of HAIs and adherence to bundles were recorded on a digital platform to be analyzed in order to direct the necessary actions to improve the team's performance.

The aggregate results of the 119 hospitals participating in the Collaborative until April 2019 have shown reductions of $41 \%$ in CLABSI, $48 \%$ in CAUTI and $28 \%$ of VAP [12].

\section{Definitions}

Surveillance of the HAIs was conducted by professionals trained in infection control, using the definitions of the
US Centers for Disease Control and Prevention - CDC [15] and their incidence was expressed as cases per 1000 devices-day, obtained by the ratio of the monthly number of cases of infection by the number of patients using the device-day related to this infection.

The utilization rate of the devices was the percentage calculated by adding the number of patients using the device-day divided by the sum of the total number of patient-days in the same period.

The percentage of adherence to bundles was assessed by dividing the number of patients observed with $100 \%$ adherence to all items in the bundle by the number of patients observed with the device.

\section{Microbiological methods}

All isolates were identified by manual or automated methods and confirmed with the Vitek 2 system (bioMerieux Vitek, Inc., Hazelwood, MO).

\section{Ethical aspects}

This research was promoted and authorized by Brazilian Ministry of Health, carried out through the Institutional Development Program of the Integrated Health System PROADI-SUS [16] and approved by the Ethics Committee of the Hospital das Clínicas - UFPE, under No. 3, 307,293 .

\section{Statistical analysis}

In the presentation of hospital characteristics, absolute and percentage frequency measurements were performed for categorical variables, and the mean and standard deviation were calculated, as well as the medians and interquartile ranges for quantitative variables. The hypothesis of normality for incidence densities (ID) was tested by the Shapiro-Wilks test, and the hypothesis of normality was accepted.

In the analysis regarding the length of stay, mortality, the IDs of VAP, CLABSIs and CAUTIs over time, Generalized Estimating Equation (GEE) model was applied for continuous variables, using the constant correlation (exchangeable) between assessments over time. The model estimated the average difference ( $\beta$ coefficient of the model) of the measures analyzed during two periods: a period in the year 2017 (prior to implementing the project) and in the years 2018 and 2019 (during the project).

The Spearman's correlation coefficient was estimated in the assessment of process indicators as explanatory variables of the behavior of the result indicators. The percentage of variation in the intervention period was based on the difference between the result indicator in January 2018 and June 2019. All tests of statistical significance were bilateral, with a significance level of 0.05 
$(p<0.05)$. All data analyzes were performed using STATA 14.

\section{Results}

\section{Characteristics of the hospitals in the study}

Five ICUs were selected by the participating hospital team totaling 48 beds in the five hospitals included in the study. Each hospital could only choose one unit to participate in the project. Three were general ICUs, one was a cardiac ICU and the other was a neurological ICU. Table 1 presents the characteristics of the studied hospitals, in which the mean number of patients-day admitted to the analyzed ICUs varied between 179 and 298 patients each month and was higher in hospitals $\mathrm{H} 1, \mathrm{H} 2$ and $\mathrm{H} 3$ when compared to hospitals $\mathrm{H} 4$ and $\mathrm{H} 5$, which presented a lower mean patient-day rate. The mean number of hospitalizations per month ranged from 23 to 31 patients. In the half-yearly assessment, there was an increase in the implementation of PDSAs in most hospitals, with hospitals H1, $\mathrm{H} 2$ and $\mathrm{H} 5$ presenting a higher percentage of total implementation when compared to the others (Table 1).

\section{Result indicators}

With regard to the group of the 5 ICUs studied, over the 18 -month period, there was no variation in relation to mortality (2017: $\beta=-0.889(p=0.089)$ and 2018/2019: $\beta=-0.113(p=0.646))$ (Fig. 1$)$. The mean monthly time of stay decreased in $2017(\beta=-0.292(p=0.033))$ and $2018(\beta=-0.276(p=0.047))$ although in the 6 months of 2019 there was an increase, with no statistical significance $(\beta=1.399(p=0.183))$. During the intervention, there was a mean monthly reduction of 0.427 in the VAP ID $(p=0.002)$ with a $33.8 \%$ decrease at the end of the period, and 0.351 in the CAUTI ID $(p=0.009)$, which corresponded to a $45 \%$ decrease at the end. There was a mean monthly reduction of the CLABSI ID of 0.252 , which was not significant $(p=0.068)$ (Table 2$)$.

\section{Process indicators \\ VAP}

The drop in the rate of monthly percentage utilization of mechanical ventilation in the 5 ICUs from $61.2+5.5$ to $54.5+5.1(p=0.002)$ demonstrated a correlation with around $50 \%(r=0.485, p=0.007)$ in the final drop of the VAP ID of $33.8 \%$. A low adherence to the preventive measures was recorded (median 48\%) and no correlation with the ID $(0.079, p=0.487)$. There was no correlation between the number of monthly meetings held and the VAP ID (Table 3). Description by hospital regarding the utilization rate of mechanical ventilation and adherence

Table 1 Characteristics of the five hospitals assessed from January 2018 to June 2019

\begin{tabular}{|c|c|c|c|c|c|}
\hline Characteristics & $\mathrm{H} 1$ & $\mathrm{H} 2$ & H3 & $\mathrm{H} 4$ & H5 \\
\hline Total number of beds & 234 & 444 & 170 & 415 & 413 \\
\hline Number of beds in ICU & 30 & 31 & 30 & 17 & 12 \\
\hline Number of beds studied & 10 & 10 & 10 & 10 & 8 \\
\hline Type of ICU studied & Cardiology & General & Neurology & General & General \\
\hline Patient-day ICU admissions per month ${ }^{\text {ab }}$ & $\begin{array}{l}291 \pm 22(216- \\
306)\end{array}$ & $\begin{array}{l}298 \pm 11(270- \\
310)\end{array}$ & $\begin{array}{l}297 \pm 19(210- \\
310)\end{array}$ & $\begin{array}{l}191 \pm 32(101- \\
246)\end{array}$ & $\begin{array}{l}179 \pm 22(116- \\
219)\end{array}$ \\
\hline Monthly number of ICU admissions ${ }^{a}$ & $31 \pm 8(12-45)$ & $23 \pm 7(12-45)$ & $30 \pm 8(15-51)$ & $25 \pm 5(13-33)$ & $24 \pm 6(8-33)$ \\
\hline \multicolumn{6}{|l|}{ PDSAs implemented/carried out (\% implemented) } \\
\hline $1^{\circ}$ semester & $21 / 36(58.3 \%)$ & 9/11 (81.8\%) & $3 / 49(6.1 \%)$ & $4 / 30(13.3 \%)$ & 19/30 (63.3\%) \\
\hline $2^{\circ}$ semester & $13 / 18(72.2 \%)$ & $2 / 4(50.0 \%)$ & $2 / 5(40.0 \%)$ & $11 / 25(44.0 \%)$ & $14 / 16(87.5 \%)$ \\
\hline $3^{\circ}$ semester & 8/9 (88.9\%) & $2 / 3(66.7 \%)$ & $12 / 13(92.3 \%)$ & $2 / 3(66.7 \%)$ & 4/5 (80.0\%) \\
\hline Total $^{d}$ & $42 / 63(66.7 \%)$ & $13 / 18(72.2 \%)$ & $17 / 67(25.4 \%)$ & $17 / 58(29.3 \%)$ & $37 / 51(72.5 \%)$ \\
\hline Number of monthly meetings held during the period ${ }^{c}$ & $4(3-4)$ & $1(0.25-2.75)$ & $2(1-3)$ & $1(1-3)$ & $3(3-3.75)$ \\
\hline $\begin{array}{l}\text { Percentage of patients with daily defined objectives in } \\
I C U^{c}\end{array}$ & $100(100-100)$ & Not assessed & $31.1(13.6-66.9)$ & $53.8(50.8-56.9)$ & $100(100-100)$ \\
\hline Assessment period of the defined objectives & $\begin{array}{l}\text { Jan/19 to } \\
\text { June/19 }\end{array}$ & - & $\begin{array}{l}\text { Jan/19 to } \\
\text { June/19 }\end{array}$ & $\begin{array}{l}\text { Nov/17 to July/ } \\
18\end{array}$ & $\begin{array}{l}\text { Jan/18 to } \\
\text { June/19 }\end{array}$ \\
\hline $\begin{array}{l}\text { Percentage of patients who received daily } \\
\text { multidisciplinary visits in ICU }\end{array}$ & $100(100-100)$ & $19.9(19.1-22.1)$ & $23.1(13.5-26.9)$ & $61.5(49.7-64.0)$ & $100(100-100)$ \\
\hline Assessment period of the multidisciplinary visits & $\begin{array}{l}\text { Jan/19 to } \\
\text { June/19 }\end{array}$ & $\begin{array}{l}\text { Feb/19 to } \\
\text { June/19 }\end{array}$ & $\begin{array}{l}\text { Jun/18 to } \\
\text { June/19 }\end{array}$ & $\begin{array}{l}\text { Nov/18 to } \\
\text { June/19 }\end{array}$ & $\begin{array}{l}\text { Jan/18 to } \\
\text { June/19 }\end{array}$ \\
\hline
\end{tabular}

Mean \pm SD (min - max) in the studied ICUs

${ }^{\mathrm{b}}$ ANOVA: $p<0,001$ - significant statistical difference: $\mathrm{H} 4 \& \mathrm{H} 5 \neq \mathrm{H} 1, \mathrm{H} 2 \& \mathrm{H} 3$

${ }^{\mathrm{C}}$ Median (P25 - P75)

${ }^{\mathrm{d}}$ There was a significant statistical difference of the $\mathrm{H} 3$ \& $\mathrm{H} 4$ hospitals when compared to the others $(p<0.05)$ 


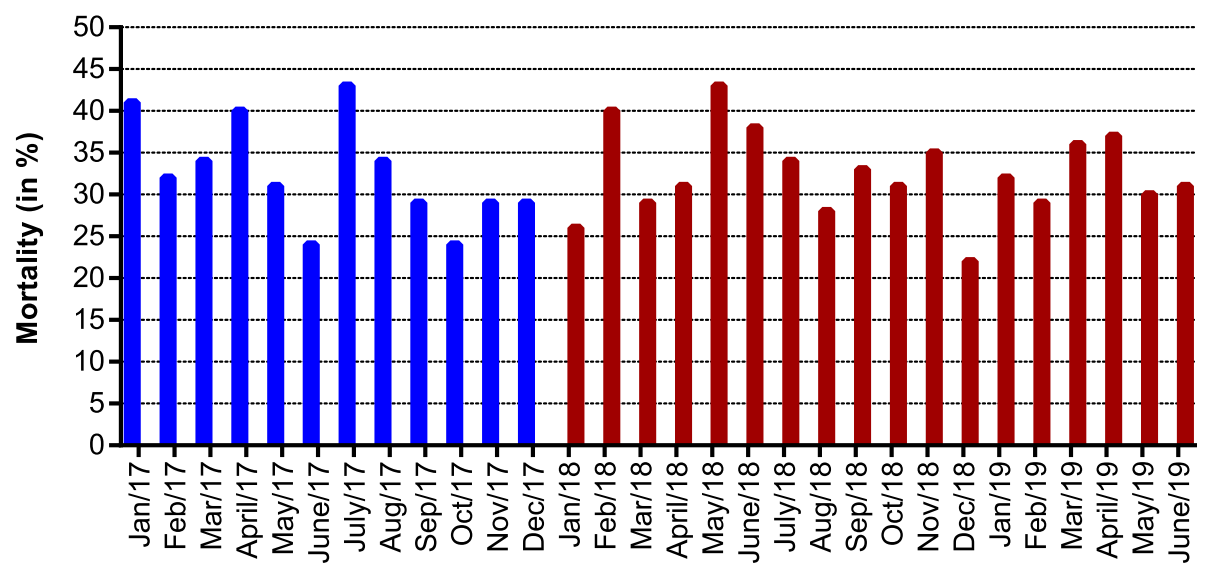

2017

2018 to 2019

Fig. 1 Mortality in ICUs of the five hospitals assessed between January 2017 and June 2019. Before intervention 2017: $\beta=-0.889(p=0.089)$ During intervention 2018 to 2019: $\beta=-0113$ ( $p=0.646)$

to the single prevention package is presented in Supplementary Table 1.

\section{CAUTI}

There was a reduction in the monthly percentage utilization rate of UCs in the 5 ICUs from $60.6 \pm 7.9$ to $43.4+6.1(p=<0.001)$ demonstrating a correlation of $37 \%(r=0.374, p=0.042)$ with the final reduction in the ID of $45 \%$. Preventive measures for UC insertion and maintenance demonstrated a median adherence of 79 and $71 \%$, respectively, and there was no correlation with the CAUTI ID. There was no correlation between the number of monthly meetings held and the CAUTI ID (Table 3). Description by hospital of the UC utilization rate and the respective adherence to the preventive insertion and maintenance measures is presented in Supplementary Table 2.

\section{CLABSI}

The monthly percentage utilization rate of the central venous catheter decreased from $81.7 \pm 3.1$ to $77.2 \pm 2.9$ $(p=<0.001)$ but there was no correlation with a reduction in the CLABSI ID. The median adherence to the preventive measures for CVC insertion of $63 \%$ correlated with $53 \%(r=-0.535, p=0.041)$ of reduction in the ID (not significant). The median adherence to the maintenance measures was $53 \%$ and there was no correlation with the ID of the infection. There was no correlation between the number of monthly meetings held and the CLABSI ID (Table 3). Description by hospital of the CVC utilization rate and respective adherence to preventive insertion and maintenance measures is presented in Supplementary Table 1.

\section{Discussion}

Our study has demonstrated that the "Improvement Model" method is effective in implementing projects for healthcare improvement in public hospitals aided by philanthropic hospitals of excellence (HE) [16]. After just a few months of preventive interventions in ICUs, a significant result was obtained in reducing VAP and CAUTIs. Internal infection control programs were already in place in ICUs, however, the incidence of HAIs remained high. Thus, this project, promoted by the Brazilian Ministry of Health, based on the improvement model of the BTS-IHI [5], provided the ICUs with an opportunity to gradually implement or ratify the preventive measures of the bundles, using a new methodology whereby participation by the areas in question (ICUs) gained prominence and empowerment over the infection prevention process [13].

The main result indicators of this quasi-experimental study, in relation to the group of 5 ICUs studied, were an average monthly decrease of $0.427(p=0.002)$ in the VAP ID and $0.351(p=0.009)$ in the CAUTI DI over a period of 18 months. The final reduction during this period of the VAP ID by $34 \%$ and the CAUTI ID by $45 \%$, is in accordance with the prevention percentages obtained in the revised multifaceted interventions, from 2005 to 2016, by Schreiber et al., also including highincome countries. The authors considered that the potential for reducing HAI by around 30 to $50 \%$, through evidence-based strategies, demonstrates that the current recommendations have not been sufficiently implemented [17]. The mean monthly reduction of CLABSI ID by $0.218(p=0.07)$ was not significant, although it demonstrated a downward trend and reflects the need for more follow-up time for this measure. It is probable that the moderate adherence to the preventive measures 
Table 2 Incidence densities of HAls in the ICUs analyzed before and during intervention

\begin{tabular}{|c|c|c|c|c|}
\hline Result indicators & $\begin{array}{l}\text { Before intervention } \\
2017\end{array}$ & $\begin{array}{l}\text { During intervention } \\
2018-2019\end{array}$ & $P$-value & Variation $\%$ \\
\hline \multicolumn{5}{|l|}{ Incidence density of VAP } \\
\hline \multicolumn{5}{|l|}{ Variation over time } \\
\hline Coefficient $\beta$ ( $p$-value) & $-0.040(0.934)$ & $-0.427(0.002)$ & - & $\downarrow 33.8 \%$ \\
\hline \multicolumn{5}{|l|}{ Assessment by hospital ${ }^{b}$} \\
\hline$H 1^{\mathrm{a}}$ & $-3.784(0.349)$ & $-0.630(0.069)$ & 0.123 & \\
\hline $\mathrm{H} 2$ & $-2.143(0.151)$ & $-0.825(0.015)$ & 0.019 & \\
\hline $\mathrm{H} 3$ & $0.004(0.988)$ & $-0.302(0.287)$ & 0.568 & \\
\hline $\mathrm{H} 4$ & $-0.679(0.135)$ & $-0.040(0.862)$ & 0.323 & \\
\hline $\mathrm{H} 5$ & $1.167(0.070)$ & $-0.337(0.302)$ & 0.114 & \\
\hline \multicolumn{5}{|l|}{ Incidence density of CAUTI } \\
\hline \multicolumn{5}{|l|}{ Variation over time } \\
\hline Coefficient $\beta$ ( $p$-value) & $0.300(0.292)$ & $-0.351(0.009)$ & - & $\downarrow 45.0 \%$ \\
\hline \multicolumn{5}{|l|}{ Assessment by hospital ${ }^{b}$} \\
\hline$H 1^{\mathrm{a}}$ & $-1.131(0.530)$ & $-0.720(0.012)$ & 0.035 & \\
\hline $\mathrm{H} 2$ & $0.097(0.688)$ & $-0.859(<0.001)$ & $<0.001$ & \\
\hline $\mathrm{H} 3$ & $0.624(0.252)$ & $-0.479(0.036)$ & 0.057 & \\
\hline $\mathrm{H} 4$ & $0.191(0.256)$ & $0.264(0.377)$ & 0.355 & \\
\hline $\mathrm{H} 5$ & $-0.282(0.490)$ & $-0.111(0.304)$ & 0.439 & \\
\hline \multicolumn{5}{|l|}{ Incidence density of CLABSI } \\
\hline \multicolumn{5}{|l|}{ Variation over time $^{b}$} \\
\hline Coefficient $\beta$ ( $p$-value) & $0.251(0.333)$ & $-0.252(0.068)$ & - & NS \\
\hline \multicolumn{5}{|l|}{ Assessment by hospital ${ }^{b}$} \\
\hline $\mathrm{H} 1^{\mathrm{a}}$ & $2.611(0.016)$ & $0.059(0.841)$ & 0.055 & \\
\hline $\mathrm{H} 2^{\mathrm{a}}$ & $0.296(0.275)$ & $-0.202(0.152)$ & 0.198 & \\
\hline $\mathrm{H} 3$ & $-0.171(0.745)$ & $0.021(0.905)$ & 0.942 & \\
\hline $\mathrm{H} 4$ & $0.118(0.699)$ & $-0.748(0.022)$ & 0.067 & \\
\hline $\mathrm{H} 5$ & $-0.181(0.386)$ & $-0.408(0.308)$ & 0.408 & \\
\hline
\end{tabular}

NS No significant variation

${ }^{a}$ Before the intervention the date for the period between July and December 2017 (6 months)

${ }^{b}$ Linear regression model for each period

for CLABSIs (63 and 53\%), even resulting in a reduction in the monthly percentage of the CVC utilization rate from $81.7 \pm 3.1$ to $77.2 \pm 2.9(p=<0.001)$ was insufficient to reduce the incidence of CLABSIs. Our result coincides with the findings of a large study on implementing the CLABSIs bundle in ICUs in the USA, which demonstrated that CLABSIs are only reduced when adherence to the bundle is at least 95\% [18].

The length of stay and mortality throughout the 18 months did not significantly decrease. In part, this may signify that patient death with HAIs is not always only attributed to this adverse event [19] and, since there are multiple causes, the role of infection is not always clear [4]. However, since it is indisputable that HAIs increase mortality and hospital stay [20] we believe that the reductions obtained in the ID were not sufficient to alter the length of stay and mortality in the ICUs.

With regard to the process indicators in the prevention of VAP, a decrease was observed in the rate of the monthly percentage utilization of mechanical ventilation in the 5 ICUs, from $61.2 \pm 5.5$ to $54.5 \pm 5.1(p=0.002)$ which correlates with around $50 \%(0.4 \overline{8} 5, p=0.007)$ of the reduction, at the end of the period, in the VAP ID. The importance of the utilization rate and its reduction explain the significant reduction in VAP ID even with insufficient adherence to the bundle [21]. However, it is important to emphasize that the median of $38 \%$ adherence to the preventive measures of VAP is not realistic, since there occurred a divergence in the understanding of the cuff pressure measurement methodology, thereby 
Table 3 Analysis of the process indicators in relation to the IDs of the HAls

\begin{tabular}{|c|c|c|c|c|}
\hline Process indicators & $\begin{array}{l}\text { Before intervention } \\
2017\end{array}$ & $\begin{array}{l}\text { During intervention } \\
2018-2019\end{array}$ & $P$-value & Correlation coefficient ( $p$-value) \\
\hline \multicolumn{5}{|c|}{ Mechanical ventilation utilization rate } \\
\hline Mean $\pm S D$ (in days) & $61.2 \pm 5.5$ & $54.5 \pm 5.1$ & 0.002 & $0.485(0.007)^{c}$ \\
\hline \multicolumn{5}{|c|}{ Adherence to preventive measures of VAP (in \%) } \\
\hline Median $\left(P_{25}-P_{75}\right)$ & - & $48(12-84)$ & - & $0.079(0.487)$ \\
\hline \multicolumn{5}{|c|}{ Number of monthly meetings } \\
\hline Median $\left(P_{25}-P_{75}\right)$ & - & $2.7(1.8-3.2)$ & - & $0.049(0.847)$ \\
\hline \multicolumn{5}{|l|}{ UC utilization rate } \\
\hline Mean \pm SD (in days) & $60.6 \pm 7.9$ & $43.4 \pm 6.1$ & $<0.001$ & $0.374(0.042)$ \\
\hline \multicolumn{5}{|c|}{ Adherence to preventive measures for INSERTION of UC (in \%) } \\
\hline Median $\left(P_{25}-P_{75}\right)$ & & $79(50-100)$ & - & $-0.169(0.138)^{d}$ \\
\hline \multicolumn{5}{|c|}{ Adherence to preventive measures for MAINTENANCE of UC (in \%) } \\
\hline Median $\left(P_{25}-P_{75}\right)$ & - & $71(60-77)$ & - & $0.289(0.342)$ \\
\hline \multicolumn{5}{|c|}{ Number of monthly meetings } \\
\hline Median $\left(P_{25}-P_{75}\right)$ & - & $2.7(1.8-3.2)$ & - & $0.195(0.437)$ \\
\hline \multicolumn{5}{|l|}{ CVC utilization rate } \\
\hline Mean $\pm S D$ (in days) & $81.7 \pm 3.1$ & $77.2 \pm 2.9$ & $<0.001$ & $-0.199(0.291)^{b}$ \\
\hline \multicolumn{5}{|c|}{ Adherence to preventive measures for INSERTION of CVC (in \%) } \\
\hline Median $\left(P_{25}-P_{75}\right)$ & - & $63(53-73)$ & - & $-0.535(0.041)^{b}$ \\
\hline \multicolumn{5}{|c|}{ Adherence to preventive measures for MAINTENANCE of CVC (in \%) } \\
\hline Median $\left(P_{25}-P_{75}\right)$ & - & $53(47-58)$ & - & $0.005(0.986)$ \\
\hline \multicolumn{5}{|c|}{ Number of monthly meetings } \\
\hline Median $\left(P_{25}-P_{75}\right)$ & - & $2.7(1.8-3.2)$ & - & $0.288(0.264)$ \\
\hline
\end{tabular}

${ }^{\mathrm{a} D a t a}$ collection on adherence to the preventive measures took place from July/2018

${ }^{\mathrm{b}}$ Correlation with CLABSI ID

'Correlation with VAP ID

${ }^{\mathrm{d} C o r r e l a t i o n}$ with CAUTI ID

negatively interfering with the assessment of the adherence to the bundle. In summary, the $35 \%$ reduction in the VAP ID was associated with a drop in the utilization of mechanical ventilation $(r=0.485, p=0.007)$, and a possible contribution from other preventive measures although registered at low levels.

In processes involving the prevention of CAUTI, there was also a significant decrease in the monthly percentage utilization of UCs in the 5 ICUs, from $60.6 \pm 7.9$ to $43.4 \pm 6.1(p=<0.001)$ representing a $37 \%$ correlation with a reduction in the CAUTI ID at the end of the period $(0.374, p=0.042)$. Adherence to the preventive measures for insertion and maintenance of the UC presented a median of 79 and $71 \%$, respectively, and there was no correlation with the CAUTI ID. As Titsworth demonstrated, there is a linear relationship between the UC utilization rate and the CAUTI ID that explains the $45 \%$ reduction in the ID [22].

Unlike most intervention projects that aim to reduce just one or two HAIs, [8, 17] our study has demonstrated that it is possible to confront 3 HAIs while at the same time expanding interventions. This aspect is corroborated by the work of Miller et al. [23] when relevant reductions were obtained in ICUs of the 3 HAIs over an intervention period of 2 years and in the same follow-up period. This seeks to improve care and the overall safety culture in the work unit, since it is known that there are many other infections that have been generated by health care, little studied in projects [17], which indirectly may be avoided by improving the patient care.

The data on infections were collected by the hospitals themselves by trained professionals, using the criteria of the CDC [15]. Differences among hospitals in relation to the adherence to the strategies proposed, as well as the number of monthly meetings can be explained by the characteristics of the hospitals in the study (Table 1) and because some diverse aspects, such as: scarce or existing resources, including human resources, willingness and availability of the ICU team management.

The major flaws in executing the project were those related to registering and adherence to bundles, which did not occur in the expected frequencies (Table 3), and 
which differs from the improvement results of the VAP and CAUTI IDs. Thus, in contrast to the improvement in results, we also observed that some items in the bundles were not executed, there was an insufficient number of audits and that executing professionals failed to complete the medical records. Additionally, the hospitals participating in this research considered that the methodology for measuring the cuff pressure of the orotracheal tube produced measurement inconsistencies, which should have been standard, thereby temporarily affecting the faithful measurement of adherence. All these facts explain the difficulty in assessing the true adherence to bundle items and therefore the registered values (supplementary tables 1 and 2) may not demonstrate the real adherence to the bundles. Certainly, the gaps in execution are related to the results, although the exact preventive contribution of each item in the bundles is unknown [17]. It is our conclusion that with a lower utilization of devices, even with limited adherence to the bundles, there was a significant reduction in infections.

Despite the difficulties in achieving the adherences, we found that the bundles with the best adherence were those for the prevention of CAUTI and the bundles with the worst adherence were those for the prevention of VAP. We believe that this study may be applied to other ICUs as a successful experience within a brief period of time. There are a number of limitations to this study for being quasi-experimental [24], rather than randomized, however, when planning the study, it was considered unethical to maintain a control group without receiving preventive measures.

\section{Conclusion}

Given the success in reducing VAP and CAUTI, there is no doubt regarding the success of the collaborative project, using improvement cycles. The remaining challenges are to guarantee a $95 \%$ adherence to the CLABSI prevention bundles, as well as the continued encouragement and involvement of the teams in the processes for consolidating the results. Studies like this one are fundamental for the effective evaluation of the result of the investments of public resources made within this type of financing. This partnership among public hospitals/HE may be applied to other ICUs including countries with fewer resources.

\section{Supplementary Information}

The online version contains supplementary material available at https://doi. org/10.1186/s12879-021-05896-0

Additional file 1: Supplementary Table 1. CVC and mechanica ventilation utilization rates and adherence to the preventive measures bundles. Supplementary Table 2. UC utilization rate and adherence to the preventive measures bundles.

\section{Abbreviations}

BTS: Breakthrough Series Collaborative method; CAUTIs: Catheter-related urinary tract infections; CDC: US Centers for Disease Control and Prevention; CLABSIs: Central line-associated bloodstream infections; CVC: Central venous catheter; GEE: Generalized Estimating Equation; HAls: Healthcare-associated infections; HE: Brazilian philanthropic hospitals of excellence; ICU: Intensive care units; ID: Incidence density; IHI: Institute of Healthcare Improvement; PDSA: Plan-Do-Study-Act rapid cycle testing; PROADI-SUS: Institutional Development Program of the Integrated Health System; QIPs: Quality improvement programs; SUS: Integrated Health System in Brazil; UC: Urinary catheter; UFPE: Federal University of Pernambuco; VAP: Ventilator associated pneumonia

\section{Acknowledgements}

Special thanks go to Brazilian Ministry of Health and Institutional

Development Program of the Integrated Health System PROADI-SUS for providing necessary data for this study.

\section{Authors' contributions}

LWM, CLV and HRL designed the study, supervised the data collection, analysis and interpretation. MVA, BRS, MGC, MFS and MCA participated in the interpretation of results and assisted in manuscript write-up. All authors read and approved the final manuscript.

\section{Funding}

The complete research was promoted and authorized by the Brazilian Ministry of Health, carried out through the Institutional Development Program of the Integrated Health System PROADI-SUS. This study was privately funded by the first author.

\section{Availability of data and materials}

The data that support the findings of this study are available from Brazilian Ministry of Health and Institutional Development Program of the Integrated Health System - PROADI-SUS but restrictions apply to the availability of these data, which were used under license for the current study, and so are not publicly available. Data are however available from the authors upon reasonable request and with permission of Brazilian Ministry of Health and Institutional Development Program of the Integrated Health System - PROADI-SUS.

Ethics approval and consent to participate

Access to the raw data used in this research was authorized by the Ministry of Health, carried out through the Institutional Development Program of the Integrated Health System PROADI-SUS [16] and approved by the Ethics Committee of the Hospital das Clínicas - UFPE, under No. 3,307,293. The data used in this study was anonymised before its use.

Consent for publication

Not applicable.

\section{Competing interests}

The authors declare that they have no competing interests.

\section{Author details}

${ }^{1}$ Clinics Hospital of Pernambuco, Federal University of Pernambuco, Recife, Pernambuco, Brazil. ${ }^{2}$ Oswaldo Cruz Hospital, University of Pernambuco, Recife, Pernambuco, Brazil. ${ }^{3}$ PROCAPE Hospital, University of Pernambuco, Recife, Pernambuco, Brazil. ${ }^{4}$ Pelopidas Silveira Metropolitan Hospital, Recife, Pernambuco, Brazil. ${ }^{5}$ Getulio Vargas Hospital, Recife, Pernambuco, Brazil.

${ }^{6}$ Department of Clinical Medicine, Federal University of Pernambuco, Recife, Pernambuco, Brazil.

Received: 7 July 2020 Accepted: 12 February 2021

Published online: 25 February 2021

\section{References}

1. Allegranzi B, Nejad SB, Combescure C, Graafmans W, Attar H, Donaldson L, Pittet D. Burden of endemic health-care-associated infection in developing 
countries: systematic review and meta-analysis. Lancet. 2011;337:228-41. https://doi.org/10.1016/S0140-6736(10)61458-4.

2. Brasil. Boletim Segurança do Paciente e Qualidade em Serviços de Saúde $n^{\circ}$ 16: Avaliação dos indicadores nacionais das Infecções Relacionadas à Assistência à Saúde (IRAS) e Resistência microbiana do ano de 2016. 2017. https://www20.anvisa.gov.br/segurancadopaciente/index.php/publicacoes/ item/boletim-seguranca-do-paciente-e-qualidade-em-servicos-de-saude-n-1 6-avaliacao-dos-indicadores-nacionais-das-infeccoes-relacionadas-a-a ssistencia-a-saude-iras-e-resistencia-microbiana-do-ano-de-2016. Accessed 30 Jan 2018.

3. European Centre for Disease Prevention and Control. Annual epidemiological report 2016 - healthcare-associated infections acquired in intensive care units. 2017. https://www.ecdc.europa.eu/en/publications-da ta/healthcare-associated-infections-intensive-care-units-annualepidemiological-0. Accessed 2 Feb 2018.

4. Umscheid CA, Mitchell MD, Doshi JA, Agarwal R, Williams K, Brennan PJ. Estimating the proportion of healthcare-associated infections that are reasonably preventable and the associated mortality and costs. Infect Control Hosp Epidemiol. 2011;32:101-14 https://pubmed.ncbi.nlm.nih. gov/21460463/. Accessed 2 Feb 2018.

5. Institute for Healthcare Improvement. The breakthrough series: IHI's collaborative model for achieving breakthrough improvement. 2014. http:// www.hi.org/resources/Pages/IHIWhitePapers/TheBrea kthroughSeries|HIsCollaborativeModelforAchievingBrea kthroughlmprovement.aspx. Accessed 4 Mar 2018.

6. Hulscher M, Schouten L, Grol R. QQUIP and the quality enhancing interventions project. 2009. https://www.health.org.uk/sites/default/files/ Collaboratives.pdf. Accessed 15 Mar 2018

7. Franco $L M$, Marquez $L$. Effectiveness of collaborative improvement: evidence from 27 applications in 12 less-developed and middle-income countries. BMJ Qual Saf. 2011;20:658-65. https://doi.org/10.1136/bmjqs.2010.044388.

8. Wells S, Tamis O, Gray J, Naidoo D, Bekhit M, Goldmann D. Are quality improvement collaboratives effective? A systematic review. BMJ Qual Safe. 2018:27:226-40. https://doi.org/10.1136/bmjgs-2017-006926.

9. Agência Nacional de Saúde Suplementar (Brasil). Cartilha nova organização do cuidado ao parto e nascimento para melhores resultados de saúde, Projeto Parto Adequado - fase 1 / Agência Nacional de Saúde Suplementar, Sociedade Beneficente Israelita Brasileira Hospital Albert Einstein, Institute for Healthcare Improvement. Rio de Janeiro: ANS; 2016. http://www.ans.gov. br/images/stories/Materiais_para_pesquisa/Materiais_por_assunto/web_tota I_parto_adequado.pdf. Accessed 30 Nov 2018

10. Lajolo C, Sardenberg C, Rooney K, Petenate A, Borem P, Luther K. Eficácia de uma abordagem Colaborativa na redução de infecções relacionadas com a assistência à saúde e melhoria da segurança em unidades de terapia intensiva (UTIs) brasileiras: a história do programa Salus Vitae. BMJ Qual Saf. 2017;25:998. https://doi.org/10.1136/bmjqs-2016-HHabstracts.8.

11. Instituto de Pesquisa Econômica Aplicada. Desenvolvimento Humano no Brasil tem leve crescimento entre 2016 e 2017. 2019. https://www.ipea.gov. $\mathrm{br} /$ portal/index.php?option=com_content\&view=article\&id=34681. Accessed 22 Jan 2019.

12. Ministério da Saúde. Proadi SUS. 2019. https://hospitais.proadi-sus.org.br/ projetos/78/saude-em-nossas-maos. Accessed 1 Sept 2020.

13. Brasil. Programa Nacional de Segurança do Paciente (PNSP). 2019. https:// www.saude.gov.br/acoes-e-programas/programa-nacional-de-seguranca-dopaciente-pnsp. Accessed 17 Feb 2019.

14. Brasil. Regulamenta a Lei $n^{\circ} 12.101$, de 27 de novembro de 2009, para dispor sobre o processo de certificação das entidades beneficentes de assistência social e sobre procedimentos de isenção das contribuições para a seguridade social. 2014. http://www.planalto.gov.br/ccivil_03/_Ato2011-2 014/2014/Decreto/D8242.htm. Accessed 5 Sept 2020

15. Center For Disease Control And Prevention (CDC). National Healthcare Safety Network (NHSN) patient safety component manual. 2018. https://www.cdc gov/nhsn/pdfs/pscmanual/pcsmanual_current.pdf. Accessed 25 Feb 2019.

16. Ministério da Saúde. Proadi SUS. 2019. https://www.saude.gov.br/acoes-eprogramas/proadi-sus. Accessed 3 Feb 2019.

17. Schreiber PW, Sax H, Wolfensberger A, Clack L. The preventable proportion of healthcare-associated infections 2005-2016: systematic review and metaanalysis. Infect Control Hosp Epidemiol. 2018;39:1277-95. https://doi.org/1 0.1017/ice.2018.183.

18. Yoko FE, Dick A, Perencevich EN, Pogorzelska M, Goldmann D, Stone PW. Central line bundle implementation in US intensive care units and impact on bloodstream infections. PLoS One. 2011;6:e15452. https://doi.org/10.13 71/journal.pone.0015452.

19. Muscedere JG. Mortality, attributable mortality, and clinical events as end points for clinical trials of ventilator-associated pneumonia and hospitalacquired pneumonia. Clin Infect Dis. 2010;1:120-5. https://doi.org/10.1086/ 653060

20. European Centre for Disease Prevention and Control. Incidence and attributable mortality of healthcare-associated infections in intensive care units in Europe, 2008-2012. Stockholm: ECDC; 2018. https://www.ecdc europa.eu/en/publications-data/incidence-and-attributable-mortality-hea Ithcare-associated-infections-intensive. Accessed 30 Mar 2019

21. Pulzi Júnior SA, Ferraz RRN, Lapchick MS. Pneumonia associada à ventilação mecânica como indicador de qualidade e segurança em saúde / Pulmonary infection associated with mechanical ventilation as quality indicator of safety in health. Rev Med Minas Gerais. 2016;26:1-6. https://doi.org/10.593 5/2238-3182.20160076

22. Titsworth WL, Hester J, Correia T, Richard R, Williams M, Guin P, et al. Reduction of catheter-associated urinary tract infections among patients in a neurological intensive care unit:a single institution's success. J Neurosurg. 2012;116:911-20. https://doi.org/10.3171/2011.11.jns11974.

23. Miller K, Briody C, Casey D, Kane JK, Mitchell D, Patel B, et al. Using the Comprehensive Unit-based Safety Program model for sustained reduction in hospital infections. Am J Infect Control. 2016;44:969-76. https://doi.org/1 0.1016/j.ajic.2016.02.038.

24. Grimshaw J, Campbell M, Eccles M, Steen N. Experimental and quasiexperimental designs for evaluating guideline implementation strategies. Farm Pract. 2000;1:11-6. https://doi.org/10.1093/fampra/17.suppl_1.s11.

\section{Publisher's Note}

Springer Nature remains neutral with regard to jurisdictional claims in published maps and institutional affiliations.
Ready to submit your research? Choose BMC and benefit from:

- fast, convenient online submission

- thorough peer review by experienced researchers in your field

- rapid publication on acceptance

- support for research data, including large and complex data types

- gold Open Access which fosters wider collaboration and increased citations

- maximum visibility for your research: over $100 \mathrm{M}$ website views per year

At $\mathrm{BMC}$, research is always in progress.

Learn more biomedcentral.com/submissions 